\title{
$\widehat{A}$ Madridge
}

madridge Journal of Women's Health and Emancipation

interconnecting Scientific World

Research Article

Open Access

\section{Transition into Academia: Challenges Faced by Female New Medical Educators}

\author{
Suhaila Sanip ${ }^{*}$ \\ Faculty of Medicine $\mathcal{E}$ Health Sciences, Universiti Sains Islam Malaysia, Malaysia
}

\section{Article Info}

\section{*Corresponding author:}

Suhaila Sanip

Universiti Sains Islam Malaysia

Pandan Indah, Kuala Lumpur

Malaysia

E-mail: suhaila.s@usim.edu.my

Received: August 19, 2017

Accepted: August 23, 2017

Published: August 29, 2017

Citation: Sanip S. Transition into Academia: Challenges Faced by Female New Medical Educator. Madridge J Womens Health Emancipation. 2017; 1(1): 16-21. doi: $10.18689 /$ mjwh-1000105

Copyright: @ 2017 The Author(s). This work is licensed under a Creative Commons Attribution 4.0 International License, which permits unrestricted use, distribution, and reproduction in any medium, provided the original work is properly cited.

Published by Madridge Publishers

\begin{abstract}
Gender gap in the top management of academic institution remains as a prominent issue that many institutions and agencies are trying to mitigate. Many female academics are found to be falling behind in terms of their career progressions despite the myriad of incentives currently provided. This study aims to explore the contributing factors that are perceived by female new medical educators (NMEs) as either supporting or hindering their transitional learning processes. These factors are likely to determine whether they stay or leave the academia. It is crucial that medical education providers are cognizant of such factors so that improvement measures can be offered accordingly. In this comparative longitudinal qualitative research conducted in Malaysia and the United Kingdom, NMEs were interviewed three times over one year about the factors that they perceived as affecting their learning processes during their transition into academia. It was found that life partners, family members and female mentors are the crucial factors that affected the learning of the female NMEs. The form of support however, can be different depending on the country's cultural context.
\end{abstract}

Keywords: Female academics; Family-career balance; Transition into academia.

\section{Introduction}

Over the years, many studies have been conducted to observe various aspects surrounding the challenges faced by women in academia. Despite these studies' recommendation for improving the working environment of women in academia, many challenges perpetuate, resulting in gender imbalance in the academic top positions. The learning of NMEs in the workplace could be affected by many factors, some of them include female gender [1] and racial minority [2]. These factors were likely to support or hinder NMEs' learning depending on the affordances available in the particular workplace $[3,4]$.

The early career stage is a critical transition point that is commonly associated with barriers and drawbacks. Female NMEs' are likely to be subjected to more challenges, both at the workplace and at home, due to cultural expectations around their roles in the family [5] as a majority of them are at the child-bearing age group. Early-career female researchers face a number of marginal kicks or drawbacks producing constrained career choices and preventing some of them from successfully translating their capabilities into sufficient scientific rewards and career advancement [6]. It has been shown that males are more likely to achieve tenure than their female colleagues with children [7]. The marginal kicks and drawbacks are sometimes augmented through feedback loops, where disadvantages in one context hamper women's chances of succeeding in another, and vice versa. These feedback loops have no particular starting or consummation points, and several loops may operate simultaneously to form cumulative disadvantages [6]. 
The literature has shown that stress may induce a negative impact on the learning capabilities of an adult [8,9]. It is therefore reasonable to postulate that female NMEs' face a more difficult transition. Experiencing difficulties early in an academic career, with lack of female academic mentors available to provide support, could be partially why women choose to leave academia, especially in Science, Technology, Engineering and Mathematics (STEM) disciplines [2]. Ackers (2004) argues how female academic lose opportunities to develop career and research networking, as their mobility across institutional and national boundaries may be particularly challenged due to family obligations [10]. Losing networking opportunities [11], being absent on maternity leave and working on a part-time basis could lead to women's insufficient social ties to institutional gatekeepers and more experienced research colleagues6. These key factors could probably be the explanation for the disproportionate female attrition rates [12]. As a mean of progressing in academia, participants in Wilson (2017) studies admitted that planning and developing strategies to manage periods of absence (for example maternity leave) or part time work was a pivotal factor that lead to their success [13].

This study aimed to explore what factors were perceived by NMEs, which a majority of them were females, as supporting or hindering their transitional learning processes. The initial email invitation recruited twelve female and seven male NMEs, while the snowballing technique recruited a further four female NMEs. As the researcher is also a female academic, it came to no surprise that the participants tend to focus on female-related issues during interviews, such as the challenges in achieving family-life and career balance. Although other themes also emerged from this study, only themes predicated upon the female NMEs will be reported in this article.

\section{Methods}

This study was conducted in both Malaysia and the United Kingdom using a longitudinal qualitative interview approach over a period of more than one year. The recruitment of NMEs was carried out through several means, primarily through communication with Deans of public medical schools both in Malaysia and the UK. As this study focused at the learning processes of NMEs in transition, purposive sampling was chosen to fulfil the inclusion criteria, which were the NMEs are required to possess a medical degree with less than a year of teaching experience and were actively involved in teaching medical students. The exclusion criteria were NMEs who did not satisfy any one of the requisite inclusion criterion.

NMEs that fulfilled the inclusion criteria in Malaysia and the UK were contacted via email and were invited to participate in the study. The participant information statement and informed consent form were attached in each email to ensure that each participant received adequate information explaining the purpose of the study and the extent of their involvement. Participation in the study was entirely on a voluntary basis in which participants can freely choose to withdraw if they so desire. The first and final semi-structured interviews were conducted face-to face while the second semi-structured interviews were conducted via telephone. Transcribed data was analysed thematically using an emergent coding frame.

\section{Results}

Life partners, family members and mentors were the themes that emerged across the female NMEs in this study.

\section{Life Partner}

Some of the NMEs' in this study feel that it was advantageous to have a life partner of the same profession as they can relate to the NMEs' career prospects. A life partner with a similar career was helpful to NMEs in discussing their professional development and career progression. NMEs were also able to collaborate with their life partner in terms of research and publications when the two of them worked within the same clinical discipline. However, possessing a spouse with similar profession is not without its own set of challenges. They illustrated how they had problems looking after their children when they both had to attend the same courses or conferences. As such, one of the NMEs' have to inexorably sacrifice their academic career whenever the family demands where high. Having a life partner in the same discipline could also be very challenging to some NMEs because although they can work together as collaborators, they have to refrain themselves from each other's shadows and shine in their own limelight.

"People from other professions may not be able to appreciate and understand the commitment of your profession. Whereas if it's somebody from the same profession who appreciates and understands where you're coming from, I think it makes a big difference to the harmony of the house... I feel that if my husband was not a medic, I don't think I would have been able to progress in my career as much as I have." (Aisha, UK, Interview 3)

Having a life partner from a different profession could be both advantageous and disadvantageous to NMEs. It is much simpler to plan family time together given that the spouse did not work in shifts such as the NMEs'. However, a life partner from a different career background may not be able to comprehend or relate to the workload of NMEs and this could potentially lead to marital conflict. Lucy, who was still in clinical training, for example was not ready to have a child due to her personal unwillingness to delay the progression of her career compared to her colleagues as she would have to take some time off from training to raise her child. Although her life partner had been supportive of her idea of not having children at the moment, she was also concerned that she would have more complications should she have a child at a later age. She had also been sacrificing her family time with her life partner to meet the requirements of her job and she knew that this might not be good for her marriage in the long 
run. The following quote illustrates Lucy's solicitude about trying to balance her career and her family life with her life partner:

"It takes a certain person to motivate themselves to spend all the extra time and you're willing to make a massive sacrifice ... Obviously I am a woman so I am thinking about children ... well I do my PhD ... it's quite hard to balance all these things. I think sacrificing is hard on your personal relationship at home because you spent a lot of time doing the work ... It's really hard to balance everything and you only got a finite amount of time but I think it's definitely possible but I think you have to really want to do it from within." (Lucy, UK, Interview 1)

Although Lucy thought that maternity leave would delay her career progression, other NMEs who had had taken maternity leave during their academic career had thought otherwise, believing that it only became a hindrance to their learning progression if they did not prepare beforehand. The female NMEs perceived that good planning and time management were necessary to ensure their academic work can continue to flourish even when they are on leave. Therefore, they believe that the short duration of maternity leave (two to three months) did not affect their career progression.

"You know when is the expected due date for your delivery ... unless you need to submit something during your maternity leave then you can think of that [maternity leave] as an obstacle for you but then for me no because I worked before that... I prepared everything so that I had a complete rest." (Rita, Malaysia, Interview 3)

For the NMEs in the UK, most of them took one year of maternity leave to only take a break from their clinical practice while still being very much involved it their other academic works, such as writing articles for publication, attending scientific meetings and presenting at conferences.

"I'm involved in quite a big international treatment guidelines work and papers I have to send in by the end of June so all of that ended up happening on maternity leave and revising papers in the evening and stuff like that. The [professional society] asked me to serve as a kind of liaison member to a committee that are writing guidelines for the UK. So I have been on teleconference for that guidelines group... I have been doing a few talks, which is really for my personal thing because I get paid for doing it by the drug companies... I was at the conference on Wednesday in Glasgow ... that was like a little expert workshop ... and then we got this other conference, which is related to the international treatment guidelines next week." (Ruby, UK, Interview 3)

\section{Immediate family}

Immediate family support, which in this case came from parents and parents-in-laws, was also an important factor influencing the learning of NMEs. For some NMEs in Malaysia, their retired parents-in-law were willing to look after their children when they went to work. Farah for example left her children at her parents-in law's house during the daytime. She felt that she could be more productive at work with her heart at ease knowing that her children are within safe and trusted hands as compared to leaving them to be cared by her maid or at a nursery.

"My mother-in-law takes care of my children. I fetched them at dusk... So that one is a relief that I don't have to rely on any baby sitter. I have my own family taking care of my kids. So at least my mind is at ease... whether they ate... bathed... pray..." (Farah, Malaysia, Interview 3)

In the UK, Ruby also received support from her mother, who, at one instance, accompanied her to a conference to take care of her newborn child. Ruby would not have been able to attend the conference if her mother had not supported her and gone along, because her baby was still breast-feeding.

"My little baby was going to conferences ... with my mum." (Ruby, UK, Interview 3)

NMEs who were parents felt more reposed when their immediate family members were around to lend a hand as they can thoroughly be trusted with the responsibility of temporary childcare.

\section{Female Mentors}

Some female NMEs expressed the need for female mentors to talk to regarding the expected challenges of raising a family for young academics and how such challenges should be faced or handled. They wanted to make an informed choice if they were planning to have children in their academic career, especially in the transition stage. For female NMEs, raising a family would involve taking time out for maternity leave and therefore, protraction of their career progression.

"It's really hard for women in academia ... because ... if you are going to have a child you're gonna have to have a period of time out and your peers are gonna progress in that time and when you come back you're gonna have different responsibilities and I don't think I can sacrifice the thing I am sacrificing if I have a child". (Lucy, UK, Interview 1)

As raising a family was a big decision to make, female NMEs wanted to learn from female academics which exemplify success both in raising a family and their academic career.

"I'd really like for someone to come along and say to me you know I am an academic, I am in your position, I worried about the children thing and when to have them and the timing and how it affected my career and this is what happened and ... it worked out." (Lucy, UK, Interview 1)

Lucy's personal dilemma was probably faced by other female NMEs around the world. Although not all female NMEs thought that maternity leave was stopping their career progression, for those who did, they wished for female role models to guide them on their career choices. 
The need to have female academic mentors may have been fuelled by a perception among female NMEs that family and work life balance was difficult to achieve. The opportunity to talk to successful female academics was suggested as a mean of gaining confidence that such balance could be achieved. The female NMEs also perceived that male academic mentors would not be able to understand the sacrifices female NMEs made to their motherhood and family life because the male academic mentors either did not have children of their own or they had a wife to look after their children.

"The other professor ... she's a very successful academic as a woman, 2 kids and a husband who's an anaesthetist ... she's very aware of funding schemes and she's very involved in a lot of the career... NIHR jobs and that kind of things. So she's a good person to talk to ... she's quite involved in the uni [university] side and she understands the female side so she's useful for that because the other two are both men who either don't have children or have children and a wife." (Lucy, UK, Interview 1)

The female NMEs in Malaysia did not express a strong need for female mentors possibly because they did not see motherhood as an impediment to their career.

\section{Motivation for choosing an academic career}

It was noted that some NMEs in Malaysia decided to become medical educators as it enabled them to settle down permanently in their very own hometown or in the booming urban areas. Any doctors working for the Ministry of Health are expected to move between hospitals as instructed by the ministry to fill vacant posts. However, the NMEs' can remain within the designated medical school of a particular state without being expected to relocate to other places unless they willingly choose to do so.

"The truth is [I became a medical educator] because I want to stay in [a state in the east coast of Malaysia]." (Hafizah, Malaysia, Interview 1)

As expected, this motive was prevalent among the Malaysian participants. This motive, however, was not prevalent in the UK, as doctors and NMEs' are willing to move about for new jobs or career promotions amidst the fierce job competition and uncertain job security environment of the UK.

"It depends on what I want and who to talk to and this... will be a big move, I think I need to think a bit about the move really, to be honest, Oxford or Cambridge are possible, it depends, I need to kind of pick ... and get to know people, so that's kind of the next step." (Ruby, UK, Interview 3)

The tendency for NMEs to work as medical educators in their hometown could be due to the proximity of immediate family members for support. For NMEs who opt to work as medical educators in big cities, their decision could be predicated upon the availability of jobs for their life partner and the infrastructure needed for themselves and possibly for their families.

\section{Discussion}

In this study, the female NMEs were able to negotiate their transitions into academia and achieve more in their careers when their life partners or family members provided them with emotional and childcare support. To date, there are no studies that report on the influence of support networks such as life partner and immediate family members to the learning of NMEs, even though they are consequential individuals in the NMEs' lives. The majority of the NMEs in this study were female and of childbearing age, and therefore it was unsurprising that they discussed mostly about family issues and trying to attain a harmonious work-life balance.

Previous studies of support networks or stress have concentrated on the influence of support networks or strains on health and wellbeing14. Although previous researchers postulated that supports and strains were inversely correlated, interestingly, such correlations are inexistent except for the people who were close to the person: for example, the spouse, life partner or family members $[15,16]$. When life partners or immediate family members are not supportive to the NMEs, it is possible that they could become a strain to NMEs' emotions, hence potentially hindering the NMEs' learning progression.

In this study, the female NMEs in the UK, who were on longer maternity leaves, were found to be involved in academic activities during their maternity leave, which was similar to that reported by other researcher [17]. Although the median parental leave duration taken by the graduate medical education trainees (GME) in Blair et al.'s study was only five to eight weeks, compared to one year in the UK and three months in Malaysia, the GMEs were found to be involved in research, writing scholarly papers, pursuing advanced degree or other training, mentoring students, attending conferences and studying for examination. Blair et al. (2015) argued that the female GMEs were still involved in academic activities during parental leave to ensure that their career advancement would not be halted [17]. The concern of the female GMEs about their career advancement in Blair et al.'s study is similar to the concern of some participants in this study, who appeared to be delaying pregnancy until after completion of postgraduate training.

The impact of parental leave was seen to affect women more than men although male GMEs were likely to be taking parental leave of shorter duration [17]. The lack of job security could possibly serve as the main motivation behind the continuous effort of NMEs' in their academic career even though they are on their maternity leave. The findings from Blair et al. (2015) and my study indicated that studies on the full impact of parental leave on female postgraduate trainees' and NMEs' career progression are timely and very much required. The findings from such studies could help policy makers to draft policies that could ameliorate the progression of female trainees and NMEs in their career.

Some female NMEs described how their transition into academia was easier because they provided with forms of legitimate peripheral participation [18] which facilitated their 
entry into the community of practice by their very own mentors. This took the form of inviting them to attend meetings and be involved in writing papers as well as introducing them to people who could assist them in their career advancement. Female academic mentors were needed by female NMEs in this study to act as an experienced advisor who could guide them as to how to manage their family, while simultaneously be successful in an academic career. The requirement for female academic role models has been reported in the literature for many years $[1,19]$. The need for female academic role models expressed by some female NMEs in my study suggests that this perpetuating issue remains unresolved to date.

The lack of female academic role models in medical education can be attributed to a perceived delay in career progression compared to male colleagues due to maternity leave or other family commitments. Although more women are holding higher posts in academia, there is still a lack of potential female academic role models because not all senior female academics fit the role of becoming an example for others. Jessica Lober Newsome reported for the UK Resource Centre for Women in SET (Science, Engineering and Technology) and the Royal Society of Chemistry in 2008 that female academics wanted female academic role models who do not have male characteristics, must still be married and must have children [20]. This suggests that female NMEs require role models who they can identify and relate with more easily.

Medical education providers should consider the need for female role models by female NMEs more seriously. These NMEs should be given ample support as a means of retaining females in academia. However, the providence of such support, particularly in a one-on-one basis is impossible due to the shortage of eligible female mentors. Thus, it is therefore more suitable to carry out the female academic role modelling in the form of a seminar or a forum. The seminar or forum would have an added advantage for the female NMEs because they would get to meet other NMEs who share their concerns about raising a family. The environment of a seminar or a forum is also less intimidating compared to a one-to-one session. However, the department should try their upmost best in accommodating the needs of NMEs' who prefer a oneto-one session. For female NMEs who are worried that raising a family will hinder their learning progression, talking to other female academics who did not find raising family an obstacle would alleviate their worry. They could still carry on with their academic work during maternity leave, but that is entirely up to them to decide after weighing up the pros and cons of their decision.

In the UK, higher education institutions are committed to supporting women in sciences with their career, especially academics, through the Athena SWAN charter. Through membership of the Athena SWAN charter, the institutions are committed to addressing gender inequalities and the underrepresentation of women in science, technology, engineering, mathematics and medicine [21]. The female
NMEs in the UK therefore, should be aware of the charter and how their institution is committed to supporting them in their academic career. The Malaysian Ministry of Women's Affairs had also revealed plans to offer more flexible working hours for those officers who attain a minimal annual appraisal mark of more than eighty-five percent [22]. This effort is being introduced to help female officers to have a better work-life balance. The academic institution in Malaysia should also consider providing similar assistance to female NMEs in an effort to reduce the numbers of female academics leaving academia due to work-life imbalance.

\section{Conclusion}

This study has shown that female NMEs are clearly struggling in their transition from clinical practice into academia. Life partners, family members and female mentors have been identified as factors supporting the transition of female academics into academia although the form of support may be different depending on country's cultural context. The findings from this study have provided evidence to justify the need for medical education to pay more attention to female NMEs, particularly in the transition phase. When female NMEs are given the attention and support which they rightly deserve, they are likely to develop into more competent medical educators who will continue to progress in their academic career.

\section{Ethical Approval}

Ethical approvals were granted by Division of Research and Development, Ministry of Higher Education, Malaysia and the University of Leeds' Medical and Dental Educational Research Committee (EdREC). The granting of ethical approvals from Malaysia and the UK and adherence to the approvals were the assurance to the participants that this study had been conducted in an ethical manner.

\section{Acknowledgment}

I am immensely grateful to the participants in this study for their willingness to spend their precious time getting involved, and for their invaluable contributions in sharing personal experiences, thoughts and ideas, which have provided the foundation for this work.

\section{Conflict of Interest}

The author has no conflicts of interest to declare

\section{References}

1. Lease SH. Occupational Role Stressors, Coping, Support, and Hardiness as Predictors of Strain in Academic Faculty: An Emphasis on New and Female Faculty. Research in Higher Education. 1999; 40(3): 285-307.

2. Adamowicz EM. Why aren't women choosing STEM academic jobs? Observations from a small-group discussion at the 2016 American Society for Microbiology annual meeting. FEMS Microbiol Lett. 2017; 364(6). doi: 10.1093/femsle/fnx057 
3. Billett S. Workplace Curriculum: Practice and Propositions. In P. V. den B. Filip Dochy, David Gijbels, Mien Segers (Ed.), Theories of Learning for the Workplace. Oxon: Routledge. 2011.

4. Roshetsky, Lisa M, Flores A, Vekhter B, Humphrey HJ, Arora VM. No Time for Teaching? Inpatient Attending Physicians' Workload and Teaching Before and After the Implementation of the 2003 Duty Hours Regulations. Academic Medicine. 2013; 88(9): 1293-1298. doi: 10.1097/ACM.0b013e31829eb795

5. Ceci SJ, Williams WM. Understanding current causes of women's underrepresentation in science. P Natl Acad Sci USA. 2010; 108(8): 31573162. doi: $10.1073 /$ pnas. 1014871108

6. Nielsen MW. Reasons for Leaving the Academy: a Case Study on the 'Opt Out' Phenomenon among Younger Female Researchers. Gender,Work Organization. 2017; 24(2): 134-155. doi: 10.1111/gwao.12151

7. Wolfinger NH, Mason MA, Goulden M. Problems in the pipeline: Gender, Marriage, and Fertility in the Ivory Tower. Journal of Higher Education. 2008; 79(4): 388-405. doi: 10.1080/00221546.2008.11772108

8. Papp KK, Stoller EP, Sage P, Aikens JE, Owens J, Avidan A et al. The effects of sleep loss and fatigue on resident-physicians: a multi-institutional, mixed-method study. Acad. Med. 2004; 79(5), 394-406.

9. McManus IC, Keeling A, Paice E. Stress, burnout and doctors' attitudes to work are determined by personality and learning style: a twelve year longitudinal study of UK medical graduates. BMC Med. 2004; 2:29. doi: $10.1186 / 1741-7015-2-29$

10. Jöns Heike. Feminizing the University: The mobilities, Careers, and Contributions of Early Female Academics in the University of Cambridge, 1926-1955. The Professional Geographer. 2017; doi: 10.1080/00330124.2017.1289778

11. Ackers L. Managing work and family life in peripatetic careers: the experiences of mobile women scientists in the European Union. Women's Studies International Forum. 2004; 27(3): 189-201.

12. Etzkowitz $\mathrm{H}$, Kemelgor $\mathrm{C}$, Uzzi B. Athena unbound: The advancement of women in science and technology. Cambridge University Press. 2000.
13. Wilson C, Broughan C, Hillier R. A new lens on a persistent problem: using emergent theory to investigate the barriers to progression of female STEM academics at a UK university. International Journal of Gender, Science \& Technology. 2017; 9(1).

14. Walen HR, Lachman ME. Social Support and Strain from Partner, Family, and Friends: Costs and Benefits for Men and Women in Adulthood. Journal of Social and Personal Relationships. 2000; 17(1). doi: $10.1177 / 0265407500171001$

15. Abbey A, Abramis DJ, Caplan D. Effects of Different Sources of Social Support and Social Conflict on Emotional Well-Being. Basic and Applied Social Psychology. 1985; 6(2):111-129. doi: 10.1207/s15324834basp0602_2

16. Okun M A, Keith VM. Effects of Positive and Negative Social Exchanges with Various Sources on Depressive Symptoms in Younger and Older Adults. Journal of Gerontology: Psychological Sciences. 1998; 53B (1): P4P20. doi: 10.1093/geronb/53B.1.P4

17. Blair JE, Mayer AP, Caubet SL, Norby SM, O'Connor Ml, Hayes SN. Pregnancy and Parental Leave During Graduate Medical Education. Acad Med. 2016; 91(7): 972-978. doi: 10.1097/ACM.0000000000001006

18. Lave J, Wenger E. Situated learning: Legitimate peripheral participation. Cambridge: Cambridge University Press. 1991.

19. Valantine $\mathrm{H}$, Sandborg $\mathrm{Cl}$. Changing the culture of academic medicine to eliminate the gender leadership gap: $50 / 50$ by 2020. Acad Med. 2013; 88(10): 1411-3. doi: 10.1097/ACM.0b013e3182a34952

20. Newsome JL. The chemistry PhD: The impact on women's retention. A report for the UK Resource Centre for Women in SET and the Royal Society of Chemistry. 2008; 1-40.

21. Athena SWAN Charter. 2017.

22. Waktu kerja anjal bantu kerja pejabat dari rumah. Kuala Lumpur. Utusan Online. (2015). 